AIAA 99-1044

Analysis and Testing of High Temperature

Fibrous Insulation for Reusable Launch

Vehicles

Kamran Daryabeigi

NASA Langley Research Center

Hampton, VA

$3^{\text {th }}$ AIAA Aerospace Sciences

Meeting and Exhibit

January 11-14, 1999 / Reno, NV 


\title{
ANALYSIS AND TESTING OF HIGH TEMPERATURE FIBROUS INSULATION FOR REUSABLE LAUNCH VEHICLES
}

\author{
Kamran Daryabeigi* \\ NASA Langley Research Center \\ Hampton, Virginia 23681
}

\begin{abstract}
$\underline{\text { Abstract }}$
Analytical models were developed to model the heat transfer through high-temperature fibrous insulation used in metallic thermal protection systems on reusable launch vehicles. The optically thick approximation was used to simulate radiation heat transfer through the insulation. Different models for gaseous conduction and solid conduction in the fibers, and for combining the various modes of heat transfer into a local, volume-averaged, thermal conductivity were considered. The governing heat transfer equations were solved numerically, and effective thermal conductivities were calculated from the steady-state results. An experimental apparatus was developed to measure the apparent thermal conductivity of insulation subjected to pressures, temperatures and temperature gradients representative of re-entry conditions for launch vehicles. The apparent thermal conductivity of an alumina fiber insulation was measured at nominal densities of 24, 48 and $96 \mathrm{~kg} / \mathrm{m}^{3}$. Data were obtained at environmental pressures from $10^{-4}$ to 760 torr, with the insulation cold side maintained at room temperature and its hot side temperature varying up to $1000^{\circ} \mathrm{C}$. The experimental results were used to evaluate the analytical models. The best analytical model resulted in effective thermal conductivity predictions that were within $8 \%$ of experimental results.
\end{abstract}

\section{$\underline{\text { Nomenclature }}$}

A ratio of parallel to total heat conduction

c specific heat

$\mathrm{D}_{\mathrm{f}}$ fiber diameter

$\mathrm{d}_{\mathrm{g}}$ gas collision diameter

e specific extinction coefficient f solidity ratio

$\mathrm{G}$ constant

$\mathrm{k}$ thermal conductivity

$\mathrm{K}_{\mathrm{B}}$ Boltzmann constant

L thickness

$\mathrm{L}_{\mathrm{c}}$ characteristic length

$\mathrm{m}$ number of control volumes for the numerical model

$\mathrm{P}$ pressure

Pr Prandtl number

$q^{\prime \prime}$ heat flux

$\mathrm{T}$ temperature

$\mathrm{t}$ time

$\mathrm{x}$ spatial coordinate

Greek Symbols

$\alpha$ accomodation coefficient

$\beta$ extinction coefficient

$\Delta \mathrm{T}$ temperature difference across test specimen

$\varepsilon$ emittance

$\gamma$ specific heat ratio

$\lambda$ mean free path

$\rho$ density

$\sigma$ Stefan-Boltzmann constant

$\tau_{0} \quad$ optical thickness

$\underline{\text { Subscripts }}$

\begin{tabular}{ll}
\hline $\mathrm{a}$ & apparent \\
$\mathrm{c}$ & conduction \\
$\mathrm{e}$ & effective \\
$\mathrm{g}$ & gas \\
$\mathrm{r}$ & radiation \\
$\mathrm{s}$ & solid
\end{tabular}

*Aerospace Engineer, Member AIAA

Copyright (C) 1999 by the American Institute of Aeronautics and Astronautics, Inc.

No copyright is asserted in the United States under title 17, U.S. Code. The U.S. Government

has a royalty-free license to exercise all rights under the copyright claimed herein for Governmental

Purposes. All other rights are reserved by the copyright owner. 


\section{Introduction}

Metallic thermal protection systems are being considered for insulating major portions of a new generation of reusable launch vehicles (RLV). The main function of the thermal protection system (TPS) is to maintain the vehicle structural temperature within acceptable limits during re-entry aerodynamic heating. The metallic TPS consists of a metallic shell panel fabricated from high-temperature metallic alloys and is mechanically attached to the substructure. The shell is filled with lightweight, non-load-bearing, hightemperature fibrous insulation. ${ }^{1,2}$ Insulation for current metallic TPS concepts experiences environmental pressure from $10^{-2}$ to 760 torr, while the hot surface of the insulation is exposed to temperatures as high as $1000^{\circ} \mathrm{C}$.

Heat transfer through a fibrous insulation involves combined modes of heat transfer: solid conduction through fibers, gas conduction and natural convection in the space between fibers, and radiation interchange through participating media. The relative contributions of the different heat transfer modes vary during reentry. Radiation becomes more dominant at high temperatures and with large temperature gradients through the insulation, while gas conduction and natural convection contributions are minimal at low pressures and become more significant with increasing pressure. The complex coupling of the heat transfer modes makes the analysis and design of hightemperature insulation difficult.

Heat transfer through fibrous insulation has been investigated by various researchers in the last 40 years, but the majority of the work has been limited to small pressure and temperature ranges. Verschoor, et al., ${ }^{3}$ experimentally and theoretically studied heat transfer through fibrous insulation over a wide pressure range, but only for temperatures up to $150^{\circ} \mathrm{C}$. Larkin and Churchill $1^{4}$ performed an experimental and theoretical study of heat transfer in fibrous insulation at 760 torr and temperatures up to $400^{\circ} \mathrm{C}$. Hager and Steere ${ }^{5}$ modeled the heat transfer through fibrous insulation and compared it with experimental results at room temperature at a pressure of $10^{-4}$ torr. Bankvall ${ }^{6}$ provided a theoretical simulation of heat transfer through building insulation and compared it with experimental results obtained at pressures from $10^{-3}$ to 760 torr, and at temperatures up to $80^{\circ} \mathrm{C}$. Pawel, et al., ${ }^{7}$ modeled the heat transfer through fibrous insulation and compared it with experimental results for pressures between 40 and 760 torr and temperatures up to $930^{\circ} \mathrm{C}$. Williams and Curry ${ }^{8}$ have provided a theoretical formulation of heat transfer through rigid fibrous insulation. Tong, et al., ${ }^{9}$ modeled heat transfer through insulation at atmospheric pressure with temperatures up to $150^{\circ} \mathrm{C}$.
The goal of the present research is to evaluate various analytical models for calculating effective thermal conductivity in fibrous insulation by comparing predicted values with measured values of apparent thermal conductivity. To facilitate this evaluation, a thermal conductivity apparatus was developed for measuring apparent thermal conductivity of hightemperature fibrous insulation at pressures from $10^{-4}$ to 760 torr, and temperatures up to $1000^{\circ} \mathrm{C}$. This paper describes the analytical formulation for heat transfer in fibrous insulation, the experimental apparatus for measuring the apparent thermal conductivity, and the comparison of measured and predicted thermal conductivities.

\section{Analytical Model}

The heat transfer mechanisms in fibrous insulation include solid conduction, gas conduction, natural convection, and radiation. Natural convection is significant at environmental pressures above one torr. In the present study, the insulation is assumed to be confined between two large horizontal plates, with the bottom plate having a lower surface temperature than the top plate. This assumption eliminates natural convection heat transfer.

A continuum model for conservation of energy in one-dimensional heat transfer in an insulation by conduction and radiation yields the partial differential equation: ${ }^{11}$

$$
\rho c \frac{\partial \mathrm{T}}{\partial \mathrm{t}}=\frac{\partial}{\partial \mathrm{x}}\left(\mathrm{k}_{\mathrm{c}} \frac{\partial \mathrm{T}}{\partial \mathrm{x}}\right)-\frac{\partial \mathrm{q}_{\mathrm{r}}^{\prime \prime}}{\partial \mathrm{x}}
$$

Two boundary conditions and an initial condition are needed to complete the problem statement. The insulation is assumed to be at a uniform initial temperature, and constant temperature boundary conditions are assumed to simulate the hot and cold surfaces of the steady-state thermal conductivity apparatus.

\section{$\underline{\text { Radiation }}$}

In its most general form, the radiant heat flux, $\mathrm{q}_{\mathrm{r}}^{\prime \prime}$, is defined by a system of simultaneous differential and integral equations. Various techniques have been used for addressing the radiation component of heat transfer through insulation. The optically thick approximation is valid for optical thickness much larger than unity. The optical thickness is defined as the ratio of the characteristic length to photon mean free path. Because the optical thickness of the insulation samples used in this study varied from 13 to 86 , the optically thick approximation was used. By assuming a gray medium 
and utilizing the optically thick approximation, the radiant flux can be reduced to: ${ }^{11}$

$$
\mathrm{q}_{\mathrm{r}}^{\prime \prime}=-\frac{16 \sigma}{3 \beta} \mathrm{T}^{3} \frac{\partial \mathrm{T}}{\partial \mathrm{x}}
$$

This formulation is valid in the interior of the medium but not at the boundaries, because it does not include any terms for radiation from the bounding surfaces. Despite this limitation, it is assumed that the formulation is applicable over the entire domain. A radiant thermal conductivity can be defined as:

$$
\mathrm{k}_{\mathrm{r}}=\frac{16 \sigma}{3 \beta} \mathrm{T}^{3}
$$

The extinction coefficient, $\beta$, is the inverse of the mean penetration distance of radiation in absorbing and scattering medium, and is given by:

$$
\beta=\mathrm{e} \rho
$$

where e is the specific extinction coefficient. The variation of specific extinction coefficient of alumina fiber with temperature given by Keller and Blumenberg ${ }^{12}$ was used in the present study.

\section{$\underline{\text { Gas Conduction }}$}

Another important heat transfer mechanism in a fibrous insulation is the gas conduction in the space between fibers. The variation of thermal conductivity with temperature for various gases is well established. Two models used for the variation of gas thermal conductivity in porous media with environmental pressure are discussed. Using the temperature jump theory for heat transfer in rarefied gas flow, the gas thermal conductivity in porous media is given by: ${ }^{13}$

$$
\mathrm{k}_{\mathrm{g}}=\frac{\mathrm{k}_{\mathrm{g}}^{*}}{1+2 \frac{2-\alpha}{\alpha}\left(\frac{2 \gamma}{\gamma+1}\right) \frac{1}{\operatorname{Pr}} \frac{\lambda}{\mathrm{L}_{\mathrm{c}}}}
$$

with $\mathrm{k}_{\mathrm{g}}^{*}$ being the temperature-dependent gas thermal conductivity at atmospheric pressure. Marcussen ${ }^{14}$ has used the same formulation for modeling variation of gas thermal conductivity in fibrous insulation. The mean free path, the mean distance traveled by molecules between collisions, is given by: ${ }^{8}$

$$
\lambda=\frac{\mathrm{K}_{\mathrm{B}} \mathrm{T}}{\sqrt{2} \pi \mathrm{d}_{\mathrm{g}}^{2} \mathrm{P}}
$$

The characteristic length, $\mathrm{L}_{\mathrm{c}}$, is defined as: ${ }^{3,6}$

$$
\mathrm{L}_{\mathrm{c}}=\frac{\pi}{4} \frac{\mathrm{D}_{\mathrm{f}}}{\mathrm{f}}
$$

The solidity ratio, $\mathrm{f}$, is defined as the ratio of the density of fibrous insulation to the density of fiber parent material. As pressure approaches 760 torr, the ratio of mean free path to characteristic length in Eq. 5a approaches zero, resulting in $\mathrm{k}_{\mathrm{g}}=\mathrm{k}_{\mathrm{g}}^{*}$. The accomodation coefficient, $\alpha$, is a measure of the average efficiency of the energy exchange between gas molecules and fibers. Various values for the accomodation coefficient between zero and unity were utilized in this study to determine the optimal value.

Various researchers ${ }^{3,6,15}$ have used the following formulation for the variation of gas thermal conductivity with pressure for fibrous insulation:

$$
\mathrm{k}_{\mathrm{g}}=\frac{\mathrm{k}_{\mathrm{g}}^{*}}{1+\frac{\lambda}{\mathrm{L}_{\mathrm{c}}}}
$$

This formulation was evaluated in this study and was found to be unsatisfactory. The numerical predictions obtained using this equation rose faster with increasing pressure compared to both experimental results and numerical results obtained using Eq. 5a.

\section{$\underline{\text { Solid Conduction }}$}

The solid conduction through fibers has been modeled differently by various researchers. The model used in this study was:

$$
\mathrm{k}_{\mathrm{s}}=\mathrm{f}^{3} \mathrm{k}_{\mathrm{s}}^{*}
$$

with $\mathrm{k}_{\mathrm{s}}^{*}$ being the temperature-dependent thermal conductivity of the fiber parent material. Some researchers have used: ${ }^{15}$

$$
\mathrm{k}_{\mathrm{s}}=\mathrm{Gk}_{\mathrm{s}}^{*} \mathrm{D}_{\mathrm{f}}^{\mathrm{n}}
$$

where the constant $\mathrm{G}$ is used for dimensional consistency. Using a value of unity for the constant $G$, Eq. 8 was evaluated in the present study and found to provide comparable results with Eq. 7 with the value of the exponent, $\mathrm{n}$, set equal to 0.5 . The solid conduction model should implicitly depend on the solidity ratio, $\mathrm{f}$, so that $\mathrm{k}_{\mathrm{s}}=\mathrm{k}_{\mathrm{s}}^{*}$ when $\mathrm{f}=1$, and $\mathrm{k}_{\mathrm{s}}=0$ when $\mathrm{f}=0$. Based on this physical reasoning it was decided to use Eq. 7 in this study.

\section{Combined Thermal Conductivity}

Heat transfer through a porous medium involves a complex combination of heat transport mechanisms which varies with temperature and pressure. For the analysis of the macroscopic heat flow through heterogeneous media, various empirical and statistical approaches have been used to model local volumeaveraged properties. ${ }^{16}$ The two models used in this study were:

$$
\begin{aligned}
& \mathrm{k}=\mathrm{f}\left(\mathrm{f}^{2} \mathrm{k}_{\mathrm{s}}^{*}\right)+(1-\mathrm{f}) \mathrm{k}_{\mathrm{g}}+\mathrm{k}_{\mathrm{r}} \\
& \mathrm{k}=\mathrm{A}\left[\mathrm{fk}_{\mathrm{s}}^{*}+(1-\mathrm{f}) \mathrm{k}_{\mathrm{g}}\right]+ \\
& \quad(1-\mathrm{A}) \frac{\mathrm{k}_{\mathrm{s}}^{*} \mathrm{k}_{\mathrm{g}}}{(1-\mathrm{f}) \mathrm{k}_{\mathrm{s}}^{*}+\mathrm{fk}_{\mathrm{g}}}+\mathrm{k}_{\mathrm{r}}
\end{aligned}
$$


Eq. 9 models solid and gas conduction in parallel, ${ }^{17}$ while Eq. 10 assumes that solid and gas conduction are both in parallel and series, with A being the ratio of heat conduction that occurs in parallel. ${ }^{6,7}$ Setting $A=f^{2}$ makes the solid conduction term consistent with Eq. 7. At very low pressures where gas conduction is negligible both models then yield $\mathrm{k}=\mathrm{f}^{3} \mathrm{k}_{\mathrm{s}}^{*}+\mathrm{k}_{\mathrm{r}}$.

\section{Solution Procedure}

By using the optically thick approximation to model radiation, the conservation of energy equation is simplified to:

$$
\rho c \frac{\partial \mathrm{T}}{\partial \mathrm{t}}=\frac{\partial}{\partial \mathrm{x}}\left(\mathrm{k} \frac{\partial \mathrm{T}}{\partial \mathrm{x}}\right)
$$

The local volume-averaged thermal conductivity, $\mathrm{k}$, (Eq. 9 or 10) was incorporated in a 1-D finite volume numerical model of the governing heat transfer equation given in Eq. 11. The Crank-Nicolson implicit algorithm was used to obtain solutions to the transient diffusion equation. The constant temperature boundary conditions and the environmental pressures used in the program corresponded to the test conditions.

The numerical solution was marched in time until steady state conditions were achieved. At steady-state conditions, the effective thermal conductivity was calculated from the individual thermal conductivities for each control volume, by assuming that control volumes represent thermal resistances in series:

$$
\mathrm{k}_{\mathrm{e}}=\mathrm{m}\left(\sum_{\mathrm{i}=1}^{\mathrm{m}} \frac{1}{\mathrm{k}_{\mathrm{i}}}\right)^{-1}
$$

\section{Thermal Conductivity Apparatus}

An experimental apparatus was developed to measure the apparent thermal conductivity of insulation under steady-state conditions for comparison with analysis. The apparatus was based on the ASTM C$201^{18}$ standard. The main difference between this apparatus and the ASTM standard is that thin foil heat flux gages are used for measuring the heat flux in the present apparatus, while three guarded water calorimeters are used in the ASTM standard. The apparatus provides apparent thermal conductivity at environmental pressures from $10^{-4}$ to 760 torr, with specimen cold side temperature maintained around room temperature, and specimen hot side temperatures up to $1000^{\circ} \mathrm{C}$.

A schematic of the apparatus is shown in Figure 1. The apparatus consists of a water-cooled plate and a ceramic board picture frame shown in Figure 2. The water-cooled plate is made of aluminum and is $304.8 \times$
$304.8 \times 25.4 \mathrm{~mm}$, and has seven coolant passages across its length. A picture frame made of refractory fiber ceramic board is set on the water-cooled plate, with the insulation sample to be tested placed inside the picture frame. The ceramic board picture frame is 50.8 $\mathrm{mm}$ wide and its outside dimensions are $304.8 \times 304.8$ $\mathrm{mm}$, resulting in a test sample size of $203.2 \times 203.2$ $\mathrm{mm}$. For the tests reported here, the ceramic board picture frame, and thus the insulation sample, was 13.4 mm thick.

The apparatus uses a ceramic-fiber radiant heater which is $304.8 \times 304.8 \mathrm{~mm}$, and consists of rows of iron-chrome-aluminum heater wires. The heater surface can be heated to $1100^{\circ} \mathrm{C}$. Since the heater does not provide uniform spatial heating, it is not used to heat the test samples directly. Rather, a septum plate made of Inconel ${ }^{\mathrm{TM}} 625$ with dimensions of $304.8 \times$ $304.8 \times 6.35 \mathrm{~mm}$ is used to provide a uniform temperature boundary for the test specimen. The septum plate is placed directly on top of the test sample.

The overall assembly of the apparatus includes setting the refractory fiber ceramic board picture frame on the water-cooled plate, installing the insulation sample on the water-cooled plate, and laying the septum plate on the sample and picture frame. The radiant heater is suspended from the carbon steel frame approximately $38 \mathrm{~mm}$ above the septum plate. The whole assembly is insulated with 25.4-mm-thick refractory fiber ceramic board, with additional insulation set on top of the heater, to minimize heat losses. The apparatus is placed in a 1.5 -m-diameter, 1.5-m-long vacuum chamber capable of providing test pressures from $1 \times 10^{-4}$ to 760 torr. All tests were conducted in a gaseous nitrogen environment. Gaseous nitrogen was selected instead of air to prevent introduction of water vapor into the chamber, thus significantly reducing the time required for pumping down to very low pressures.

\section{$\underline{\text { Instrumentation }}$}

The water-cooled plate is instrumented with nine thin film heat flux gages. Each heat flux gage is 25.4$\mathrm{mm}$ long and $19.05-\mathrm{mm}$ wide, with a nominal thickness of $0.1524 \mathrm{~mm}$. The gages are thermopiles encapsulated in polyimide film, producing a voltage directly proportional to the impinging heat flux with a nominal sensitivity of $1.05 \times 10^{-6} \mathrm{~V} /\left[\mathrm{W} / \mathrm{m}^{2}\right]$. Each heat flux gage also utilizes a type $\mathrm{T}$ (copper/constantan) thermocouple for surface temperature measurement. The heat flux gages are bonded to the top of the water-cooled plate with their lead wires buried underneath the plate top surface. Two epoxy filled trenches are made in the plate for subsurface burying of the heat flux gage lead wires. 
A polyimide sheet $0.127-\mathrm{mm}$ thick covers the plate at locations not covered by heat flux gages. The polyimide sheet is bonded to the plate to provide a uniform surface on the water-cooled plate. The top surface of the polyimide sheet is spray painted using a flat black paint with an emittance of 0.92 throughout the infrared spectrum.

The septum plate is instrumented with 23 metal sheathed type K (nickel-chromium/nickel-aluminum) thermocouples. The thermocouples were installed on the top surface of the septum plate (opposite side from the insulation sample) so that uniform contact exists between the septum plate and insulation test sample. The septum plate was oxidized in an oven at $1000^{\circ} \mathrm{C}$ for 6 hours after the installation of the thermocouples. The emittance of oxidized inconel has been reported to be $0.85 .^{19}$

The thermocouple and heat flux gage data are collected using a personal computer based data acquisition system. The thermocouple data are converted to temperature using look-up tables by the data acquisition software. Raw voltages from the heat flux gages are converted to heat flux by applying a manufacturer-suggested temperature correction to the raw data and then using the manufacturer's linear calibration for heat flux versus voltage for each sensor.

\section{Data Analysis}

The apparent thermal conductivity of the sample is calculated from Fourier's law:

$$
\mathrm{k}_{\mathrm{a}}=\frac{\mathrm{q}^{\prime \prime} \mathrm{L}}{\Delta \mathrm{T}}
$$

Only the data from the central $127 \times 127 \mathrm{~mm}$ section of the test set-up, referred to as the metered region, are used for calculating the apparent thermal conductivity. There are five heat flux gages on the water-cooled plate, and 15 thermocouples on the septum plate in the metered region. The apparent thermal conductivity of the sample at each of the five heat flux gage locations in the metered region is calculated. Then, the data are averaged to obtain the average apparent thermal conductivity.
Steele. ${ }^{20}$ The overall uncertainty in the estimation of the apparent thermal conductivity is obtained by combining the precision and bias errors using the root-sum-square method.

The bias error for the thermocouples was determined by performing a comparison calibration in a controlled temperature oven/bath with a National Institute of Standard and Technology (NIST) traceable thermometer. The bias error for heat flux sensors was determined by calibration against a high intensity total irradiance standard (solar constant lamp). The precision error for the thermocouples and heat flux gages was determined from the experimental measurements, by calculating the standard deviations of the temporal variations of each measured quantity.

The bias, precision, and overall uncertainties for apparent thermal conductivity are presented in Table 1. The uncertainties are presented as a percentage of uncertainty with respect to calculated thermal conductivity. The precision uncertainties were obtained from measurements on the insulation sample at 24 $\mathrm{kg} / \mathrm{m}^{3}$, and corresponded to measurements at pressures of $1 \times 10^{-4}, 1 \times 10^{-2}$, and 760 torr, and nominal average sample temperatures of 50,300 , and $500^{\circ} \mathrm{C}$. The overall uncertainty varied from 5.5 to $9.7 \%$. The highest uncertainties were at the lowest sample average temperature.

Table 1. Overall uncertainty estimates for effective thermal conductivity.

\begin{tabular}{|r|c|c|c|c|}
\hline $\begin{array}{c}\text { Pressure } \\
\text { (torr) }\end{array}$ & $\begin{array}{c}\text { Average } \\
\text { Temperature } \\
\left({ }^{\circ} \mathrm{C}\right)\end{array}$ & $\begin{array}{c}\text { Bias } \\
\text { Error } \\
(\%)\end{array}$ & $\begin{array}{c}\text { Precision } \\
\text { Error }(\%)\end{array}$ & $\begin{array}{c}\text { Overall } \\
\text { Error } \\
(\%)\end{array}$ \\
\hline 0.0001 & 51.5 & 5.86 & 7.68 & 9.66 \\
\hline 0.01 & 51.5 & 5.86 & 7.29 & 9.35 \\
\hline 760 & 51.1 & 5.96 & 4.73 & 7.61 \\
\hline 0.0001 & 303.3 & 3.98 & 3.87 & 5.55 \\
\hline 0.0105 & 303.4 & 3.98 & 3.87 & 5.55 \\
\hline 755 & 302.8 & 3.97 & 3.85 & 5.53 \\
\hline 0.0001 & 505.0 & 3.91 & 3.82 & 5.47 \\
\hline 0.0114 & 505.2 & 3.91 & 3.84 & 5.48 \\
\hline 474 & 506.2 & 3.91 & 3.82 & 5.47 \\
\hline
\end{tabular}

To provide an independent assessment of uncertainty, the apparent thermal conductivity of a fumed silica board, Standard Reference Material (SRM) 1459 from NIST was measured using the current apparatus. The thermal conductivity of this SRM has been reported by NIST to be $0.021 \mathrm{~W} / \mathrm{mK}$ at $24^{\circ} \mathrm{C}$. The 
apparent thermal conductivity of the SRM sample was also measured using the guarded hot plate technique ${ }^{21}$ at Holometrix, Inc. at average temperatures up to $300^{\circ} \mathrm{C}$. The results of the measurements are provided in Table 2. The specimen average temperature, the measured apparent thermal conductivity, and the corresponding thermal conductivity from the guarded hot plate data are presented. The percentage difference between measurements using the current apparatus and the guarded hot plate data are also presented. It can be seen that the data from the current apparatus are within 5.5\% of the guarded hot plate data.

Table 2. Comparison of effective thermal conductivity measurements on NIST Standard Reference Material 1459 using the present apparatus and the guarded hot plate technique

\begin{tabular}{|c|c|c|c|}
\hline $\begin{array}{c}\text { Average } \\
\text { Temperature } \\
\left({ }^{\circ} \mathbf{C}\right)\end{array}$ & $\begin{array}{c}\text { Thermal } \\
\text { Conductivity } \\
\text { [present } \\
\text { apparatus] } \\
(\mathbf{W} / \mathbf{m K})\end{array}$ & $\begin{array}{c}\text { Thermal } \\
\text { Conductivity } \\
\text { [guarded hot } \\
\text { plate] } \\
(\mathbf{W} / \mathbf{m K})\end{array}$ & $\begin{array}{c}\text { Percent } \\
\text { difference } \\
(\%)\end{array}$ \\
\hline 53.4 & 0.022 & 0.0215 & 2.3 \\
\hline 53.9 & 0.022 & 0.0215 & 2.3 \\
\hline 95.4 & 0.021 & 0.0222 & 5.5 \\
\hline
\end{tabular}

\section{$\underline{\text { Results and Discussion }}$}

The numerically predicted thermal conductivities are discussed. The apparent thermal conductivity of of Saffil ${ }^{\mathrm{TM}}$, an alumina based fibrous insulation was measured at densities of 24,48 , and $96 \mathrm{~kg} / \mathrm{m}^{3}$. Tests were conducted with the septum plate temperature set at nominal temperatures of 95, 260, 425, 590, 760, 870, and $980^{\circ} \mathrm{C}$, and the environmental pressure controlled to nominal values of $1 \times 10^{-4}, 1 \times 10^{-3}, 1 \times 10^{-2}, 0.1,0.5,1,5$, 10, 100, and 750 torr. The water-cooled plate was maintained at room temperature. All tests were conducted in a gaseous nitrogen environment. The measured thermal conductivities were compared with predicted effective thermal conductivities.

\section{$\underline{\text { Numerical Results }}$}

The analytical methods described previously were used to numerically calculate effective thermal conductivities. The radiation model given in Eq. 3, the gas conduction model given in Eq. 5a and the solid conduction model given in Eq. 7 were used in the analysis. The two models for combining the various heat transfer mechanisms into local volume-averaged thermal conductivities given in Eq.'s 9 and 10 were also used. The effective thermal conductivity was calculated from local thermal conductivity using Eq. 12.

The various heat transfer mechanisms are coupled, and the net contributions of each component to the effective thermal conductivity can not be independently assessed. The contribution of each mode transfer mode to the local volume-averaged thermal conductivity calculated from Eq. 9 for each control volume in the numerical model could be assessed from steady state numerical results. The results obtained with the hot side and cold side temperatures at $1000^{\circ} \mathrm{C}$ and $20^{\circ} \mathrm{C}$, respectively, and environmental pressures of $10^{-4}$ and 100 torr are presented in Figure 3. Data presented are for an insulation sample with a thickness of $13.4 \mathrm{~mm}$ and a density of $48 \mathrm{~kg} / \mathrm{m}^{3}$. The solid conduction, gas conduction and radiation contributions to the local thermal conductivity and the local thermal conductivity are presented as a function of non-dimensional throughthickness location in insulation. The non-dimensional through-thickness locations of 0 and 1 correspond to boundary temperatures of $20^{\circ} \mathrm{C}$ and $1000^{\circ} \mathrm{C}$. Solid conduction is almost negligible. Gas conduction is negligible at $10^{-4}$ torr. At 100 torr, gas conduction has a larger contribution to thermal conductivity compared to radiation for through-thickness locations up to 0.25 . This trend reverses at through-thickness locations larger than 0.25 , with the radiation becoming more dominant with increasing temperature.

\section{Comparison of Numerical and Experimental Results}

The numerical and experimental data are first compared at low pressures, where gas conduction is negligible. This enables evaluation of models for solid conduction and radiation. Then, the numerical and experimental results are compared at higher pressures where gas conduction is significant.

\section{Thermal Conductivity in Absence of Gas}

\section{Conduction}

The analytical predictions were compared to experimental results obtained at $\mathrm{P}=10^{-4}$ torr. At this pressure solid conduction and radiation were the only heat transfer mechanisms. The local volume-averaged thermal conductivity using both Eq.'s 9 and 10 would yield:

$$
\mathrm{k}=\mathrm{f}^{3} \mathrm{k}_{\mathrm{s}}^{*}+\mathrm{k}_{\mathrm{r}}
$$

The results are shown in Figure 4, where the effective thermal conductivity is plotted versus sample average temperature for the three insulation densities. The experimentally measured apparent thermal conductivities are also presented in the figure. The error bars associated with the experimental data 
presented in all the figures corresponded to $7.5 \%$ of reading uncertainty in accordance with the experimental uncertainty data presented in Table 1 . The apparent thermal conductivity varies non-linearly with sample average temperature, increasing rapidly with increasing temperature due to the nonlinear nature of radiation heat transfer. This effect is more evident with the lower density insulation. As the density increases the solid conduction contribution increases, but the radiation heat transfer decreases more rapidly, resulting in a net decrease in the apparent thermal conductivity. The standard deviation between measured and calculated data for sample densities of 24,48 and $96 \mathrm{~kg} / \mathrm{m}^{3}$ was 8 , 6.3 and $5.4 \%$, respectively. The agreement between the numerical and experimental results improved with increasing insulation density.

For the sample density of $24 \mathrm{~kg} / \mathrm{m}^{3}$ the numerical data over-predicted the experimental results at lower temperatures. The contribution of solid conduction to the effective thermal conductivity decreases with decreasing insulation density in accordance with Eq. 14. For the lowest density insulation solid conduction was almost negligible, and the effective thermal conductivity simply consisted of radiation. Therefore, the larger discrepancy between experimental and numerical results for the lowest density insulation was simply due to the radiation model. Because the values of optical thickness are low for this low-density insulation at low temperatures, the optically thick model begins to break down. However, at higher temperatures the optical thickness of the sample increased, resulting in closer agreement between experimental and numerical results.

For sample densities of 48 and $96 \mathrm{~kg} / \mathrm{m}^{3}$, the experimental and analytical results agree within the experimental accuracy. For sample density of 24 $\mathrm{kg} / \mathrm{m}^{3}$, agreement is not as good. If more accurate predictions are required an improved radiation model must be used.

\section{Thermal Conductivity in Presence of Gas Conduction}

The analytical model for gas conduction (Eq. 5a) and the two models for combined thermal conductivity ( Eq. 9 and 10) were evaluated by comparison with experimental results with pressure values above $10^{-3}$ torr. The value of the accomodation coefficient, $\alpha$, in Eq. 5a was varied between zero and unity. The best results were obtained with $\alpha=1$, and these are the results presented here.

The variation of effective thermal conductivity with sample average temperature at environmental pressure of 100 torr for the three insulation samples is shown in Figure 5. The analytical predictions using both Eq.'s 9 and 10 were within the uncertainty range of experimental data for the three samples. The numerical results slightly under-predicted the experimental results at higher temperatures for sample densities of 24 and $48 \mathrm{~kg} / \mathrm{m}^{3}$. This could attributed to uncertainties in gas conduction model and the coupling models used for combining solid and gas conduction.

The variation of effective thermal conductivity with environmental pressure at nominal sample average temperatures of 50,220 , and $500^{\circ} \mathrm{C}$ for the three insulation densities is shown in Figures 6a through 6c. The increase in apparent thermal conductivity with increasing pressure is due to gas conduction. Gas conduction is negligible below 0.01 torr, rapidly increases between 0.1 and 10 torr, and then asymptotically approaches a constant between 10 and 760 torr. The standard deviations between measured and calculated data were 7.8 and $7.6 \%$ for the parallel model (Eq. 9) and the parallel/series model (Eq. 10), respectively. There was good agreement between analytical and experimental results for insulation density of $96 \mathrm{~kg} / \mathrm{m}^{3}$ over all temperatures and pressures, except for the data at $50^{\circ} \mathrm{C}$ at intermediate pressure levels ( 0.1 to 1 torr). The analytical results slightly under-predicted experimental results in this range. The parallel model (Eq. 9) matched the experimental results better for this insulation density. For the insulation density of $48 \mathrm{~kg} / \mathrm{m}^{3}$, there was good agreement between numerical and experimental results over all pressures at sample average temperatures of 50 and $220^{\circ} \mathrm{C}$. The numerical results under-predicted experimental results at pressures above 5 torr at $500^{\circ} \mathrm{C}$, as discussed previously. For the insulation density of $24 \mathrm{~kg} / \mathrm{m}^{3}$, the numerical results under-predicted experimental results at pressures above 10 torr at $500^{\circ} \mathrm{C}$, and over-predicted at pressures below 0.01 torr at $220^{\circ} \mathrm{C}$, as discussed previously. The parallel/series model (Eq. 10) was slightly better than the parallel model for insulation densities of 24 and $48 \mathrm{~kg} / \mathrm{m}^{3}$.

It can be concluded that the solid and gas conduction models and the two models for combined thermal conductivity produced satisfactory results. The optically thick assumption provides a good approximate technique for handling radiation heat transfer in fibrous insulation, with the accuracy of results improving with increasing insulation density. More detailed radiation models are required for more accurate modeling of fibrous insulation samples with density of $24 \mathrm{~kg} / \mathrm{m}^{3}$. Insulation tested in metallic TPS under the X-33 program $^{1}$ had a nominal density of $48 \mathrm{~kg} / \mathrm{m}^{3}$ and was several times as thick as the insulation samples tested in this study, resulting in a much higher optical thickness. Therefore, the optically thick assumption can be used for the analysis of its thermal performance. 


\section{Concluding Remarks}

The combined radiation and conduction heat transfer through fibrous insulation was solved numerically. The radiation heat transfer was modeled using the optically thick approximation. Various models for gas and solid conduction and their combination were evaluated.

An experimental apparatus was designed and fabricated to measure the apparent thermal conductivity of high temperature insulation subject to large temperature differences representative of typical launch vehicle re-entry conditions. The insulation sample cold side was maintained near room temperature, while the hot side was heated to temperatures as high as $1000^{\circ} \mathrm{C}$. The environmental pressure was varied from $1 \times 10^{-4}$ to 760 torr. The overall uncertainty for the apparent thermal conductivity measurements was between 5.5 to 9.9\%. The apparent thermal conductivity of Saffili ${ }^{\mathrm{TM}}$, an alumina fiber insulation, at nominal densities of 24 , 48 , and $96 \mathrm{~kg} / \mathrm{m}^{3}$ was measured.

The measured and predicted thermal conductivities were compared. It was found that the use of the optically thick approximation for modeling the radiation heat transfer through the insulation provided agreement within experimental accuracy over most temperatures and pressures. The agreement was not as good for the lowest density insulation sample studied. The models for gas and solid conduction and their coupling produced agreement within experimental accuracy. The best analytical model resulted in effective thermal conductivity predictions that were within $8 \%$ of experimental results for the tested range of pressures and temperatures.

\section{$\underline{\text { Acknowledgements }}$}

The author would like to thank the following NASA Langley employees for their invaluable support: Max Blosser for his guidance, Wayne D. Geouge for fabrication and instrumentation of the experimental apparatus, and Jeffrey R. Knutson for modifying and operating the vacuum chamber.

\section{List of References}

1. Blosser, M.L., Martin, C.J., Daryabeigi, K., and Poteet, C.C., "Reusable Metallic Thermal Protection System Development," Presented at the Third European Workshop on Thermal Protection Systems, ESTEC, The Netherlands, March 1998.

2. Gorton, M.P., Shideler, J.L., and Webb, G.L., "Static and Aerothermal Tests of a Superalloy
Hoenycomb Prepackaged Thermal Protection System," NASA TP-3257, March 1993.

3. Verschoor, J.D., Greebler, P., Manville, N.J., "Heat Transfer by Gas Conduction and Radiation in Fibrous Insulation," Journal of Heat Transfer, Vol. 74, August 1952, pp. 961-968.

4. Larkin, B.K., Churchill, S.W., "Heat Transfer by Radiation through Porous Insulations," American Institute of Chemical Engineers Journal, Vol. 4, No. 5, December 1959, pp. 467-474.

5. Hager, N.E., Jr., Steere, R.C., "Radiant Heat Transfer in Fibrous Thermal Insulation," gournal of Applied Physics, Vol. 38, No. 12, November 1967, pp. 4663-4668.

6. Bankvall, C., "Heat Transfer in Fibrous Materials," gournal of Testing and Evaluation, Vol. 1, No. 5, May 1973, pp. 235-243.

7. Pawel, R.E., McElroy, D.L., Weaver, F.J., Graves, R.S., "High Temperature Thermal Conductivity of a Fibrous Alumina Ceramic," Thermal Conductivity, 19, Edited by David Yarbrough, pp. 301-313, 1985, Plenum Press, New York.

8. Williams, S.D., Curry, D.M., "Prediction of Rigid Silica Based Insulation Conductivity Using Morphological Data," Presented at the $29^{\text {th }}$ National Heat Transfer Conference, Atlanta, Georgia, August 1993.

9. Tong, T.W., Tien, C.L., "Radiative Heat Transfer in Fibrous Insulations-Part I: Analytical Study," Journal of Heat Transfer, Vol. 105, February 1983, pp. 70-75.

10. Tong, T.W., Yang, Q.S., Tien, C.L., "Radiative Heat Transfer in Fibrous Insulations-Part II: Experimental Study," Journal of Heat Transfer, Vol. 105, February 1983, pp. 76-81.

11. Sparrow, E.M., Cess, R.D., Radiation Heat Transfer, Augmented Edition, 1978, McGraw-Hill, New York.

12. Keller, K., Blumenberg, J., "High Temperature Airborne Fibre Insulations Heat Transfer," Proceedings of the Ninth International Heat Transfer Conference, 1990, Edited by G. Hetsroni, pp. 479-484.

13. Kennard, E.H., Kinetic Theory of Gases, 1938, McGraw-Hill, New York.

14. Marcussen, L., "Prediction of Effective Thermal Conductivity for Fibrous Media," Thermal 
Conductivity, 19, Edited by David Yarbrough, pp. 75-84, 1985, Plenum Press, New York.

15. Cunnington, G.R., Zierman, C.A., Funai, A.I., and Lindahn, A., " Performance of Multilayer Insulation Systems for Temperatures to 700K," NASA CR-907, October 1967.

16. Kaviany, M., Principles of Heat $\mathcal{T}$ ransfer in Porous Media, 1991, Springer-Verlag, Berlin/New York/Heidelberg.

17. Schnider, P.J., "Conduction," Section 3, Handbook of Heat $\mathcal{T r a n s f e r}$ Edited by W.M. Rohsenow and J.P. Hartnet, 1973, McGraw-Hill.

18. ASTM Standard C 201: "Standard Test Method for Thermal Conductivity of Refractories," 1996 Annual Book of ASTM Standards, Vol. 15.01, Refractories, Carbon and Graphite Products, Activated Carbon Advanced Ceramics, 1996.

19. Clark, R.K., Unnam, J., "Response of Inconel 617 to Sea Salt and Re-entry Conditions," gournal of Spacecraft, Vol. 23, No. 1, Jan-Feb 1986, pp. 96101.

20. Coleman, H.W., Steele, W.G., Experimentation and Uncertainty Analysis for Engineers, 1989, Wiley, New York.

21. ASTM Standard C 177: "Standard Test Method for Steady-State Heat Flux Measurements and Thermal Transmission Properties by Means of the GuardedHot-Plate Apparatus," 1996 Annual Book of ASTM Standards, Vol. 4.06, Thermal Insulation, Environmental Acoustics, 1996.
Figure 1. Schematic diagram of thermal conductivity apparatus.

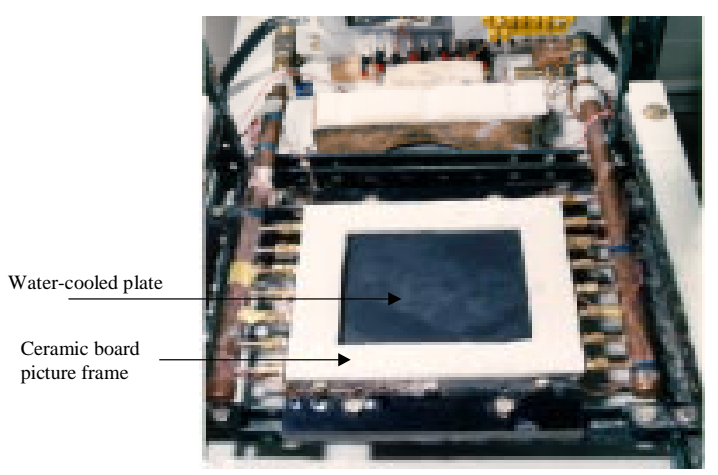

Figure 2. Photograph of thermal conductivity apparatus with picture frame set on the water-cooled plate.

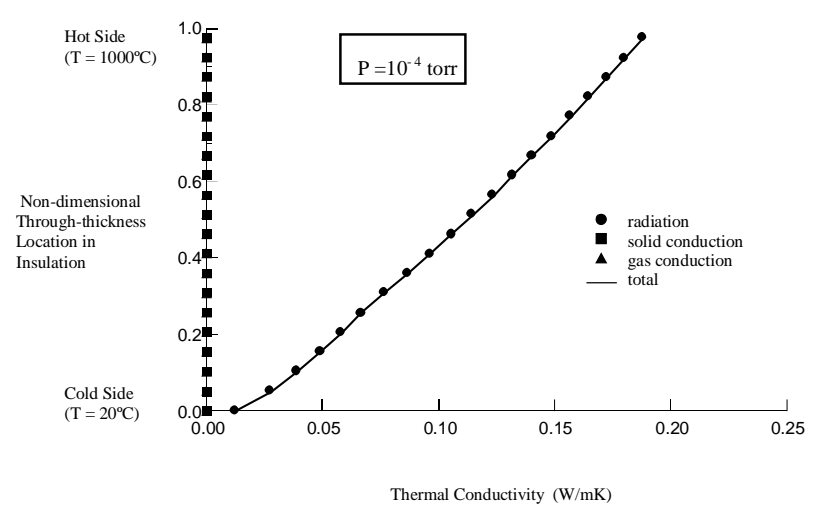

Fig. 3a

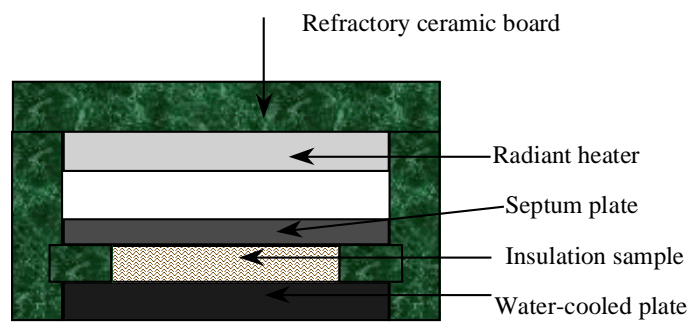




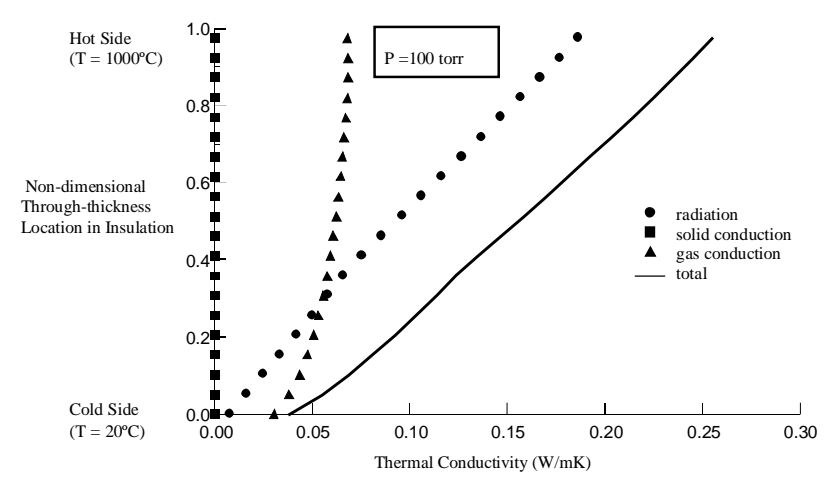

Fig. $3 b$

Figure 3. Contribution of different heat transfer mechanisms to local thermal conductivity for insulation density of $48 \mathrm{~kg} / \mathrm{m}^{3}$ with: a) $\mathrm{P}=10^{-4}$ torr, b) $\mathrm{P}=100$ torr.

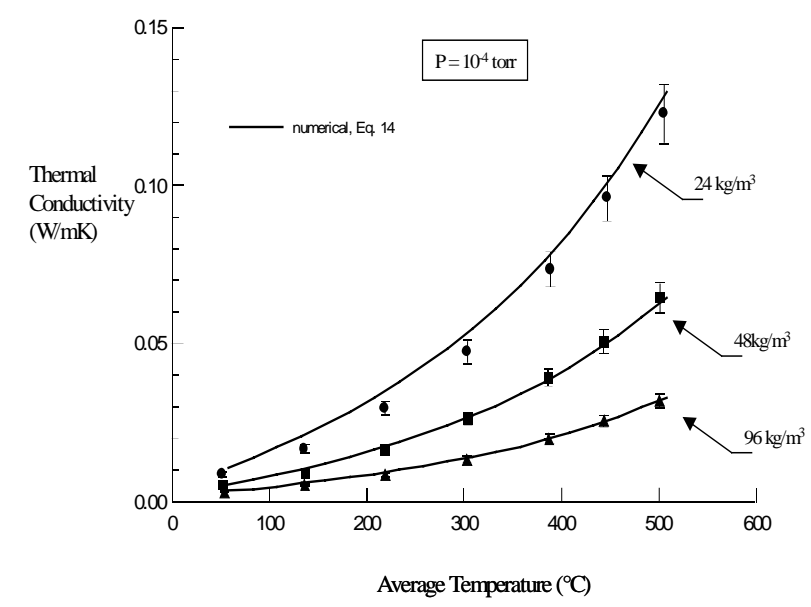

Figure 4. Comparison of numerical and experimental thermal conductivity at $10^{-4}$ torr.

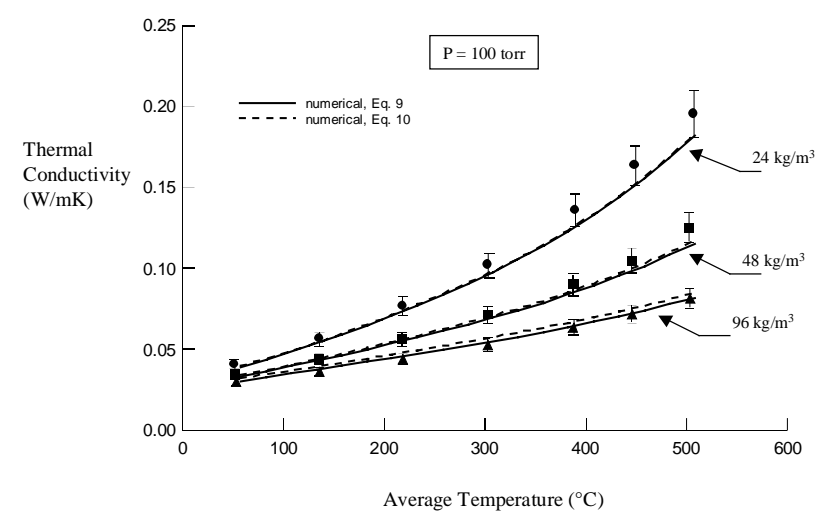

Figure 5. Comparison of numerical and experimental thermal conductivity at 100 torr.

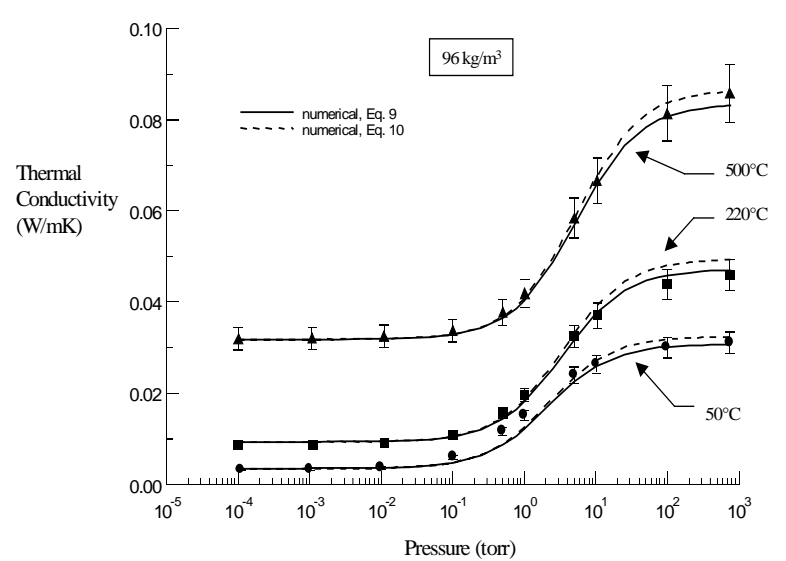

Fig. 6a

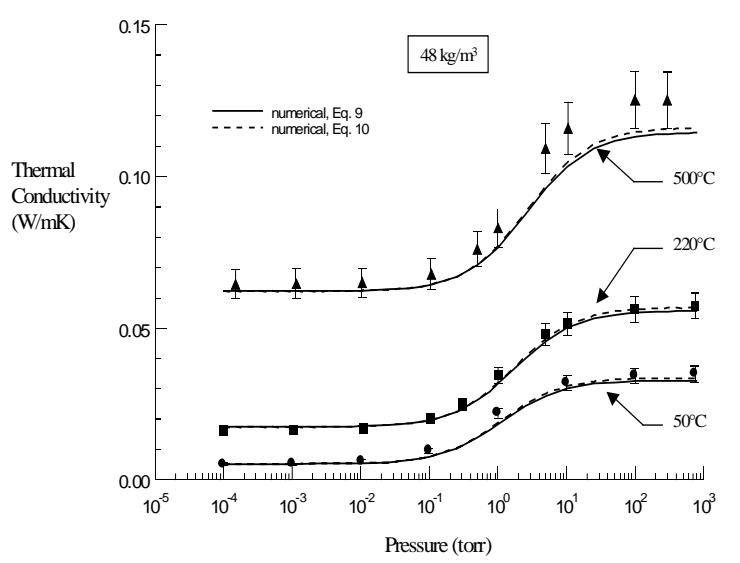

Fig. 6b

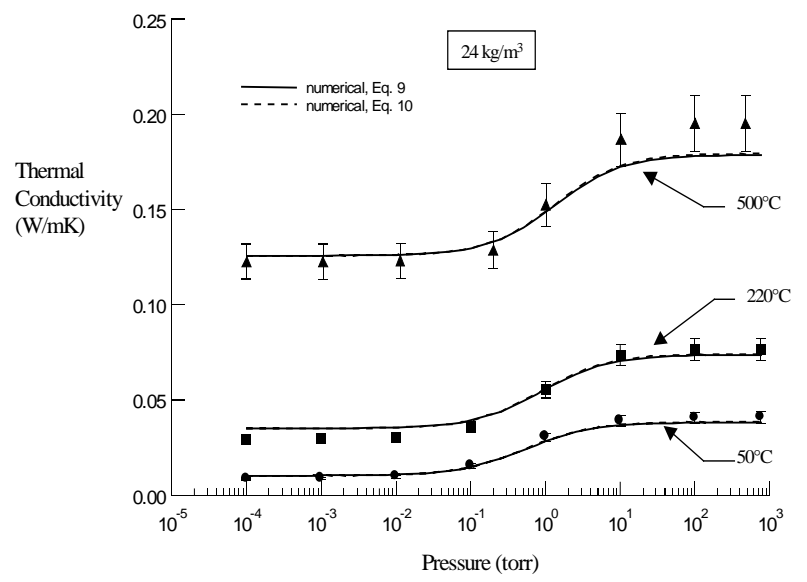

Fig. 6c

Figure 6. Comparison of numerical and experimental thermal conductivity versus pressure for insulation densities of a) 96 , b) 48 , c) $24 \mathrm{~kg} / \mathrm{m}^{3}$. 